\title{
Application of Ridit Analysis to Study the Severity of Anemia among Children, Adolescents and Pregnant Women in Andhra Pradesh
}

\author{
Naveen Kumar Boiroju*, D. Vijaya Bhaskara Rao \\ and K. Venkaiah
}

Division of Biostatistics, National Institute of Nutrition (ICMR), Hyderabad, India.

*Corresponding Author: nanibyrozu@gmail.com

Received: 30 $0^{\text {th }}$ June 2016 / Revised: $1^{\text {st }}$ May 2017/ Accepted: $/ 19^{\text {th }}$ July 2017

CIAppStat-SL2017

\begin{abstract}
Ridit analysis is a simple and a suitable method for analyzing the ordinal data, where the natural ordering of the variable under study is very important. This paper presents the utility and usefulness of the ridit analysis of the graded severity of anemia among the children and pregnant women in the Andhra Pradesh state, India. Application of ridit analysis to study the severity of anemia among the vulnerable groups in the state is sparse. The present study aims at to assess the severity of anemia among the children and pregnant women in the state and also to compare the distribution of severity of anemia among different socio-demographic characteristics of the respondents using the ridit analysis. The highest prevalence of severe anemia $(21.2 \%)$ is observed among the children (6-59 months), whereas it was around $10 \%$ in the adolescents and pregnant women in the state. From the ridit analysis, it is observed that the children and pregnant women in the rural areas of the state having a higher estimated probability of severe anemia as compared to the urban subjects. There is a lower chance of severe anemia among the children and pregnant women from the other castes as compared to the scheduled castes or tribes in the state.
\end{abstract}

Keywords: Anemia, Ordinal data, Chi-square test and Ridit analysis.

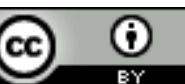




\section{Introduction}

Health and nutrition surveys measure the characteristics in mixed scales, such as, nominal, ordinal and ratio scales. The nominal variables simply categorize the subjects, for example, gender (male, female), religion (Hindu, Muslim, Christian, others) or caste, whereas, the variables on an ordinal scale (nominal with an order) include, different stages of cancer, levels of depression, graded severity of diseases and the ratings on a Likert scale (Sermeus \& Delesie; 1996). Sometimes, a quantitative variable transformed into an ordinal variable, which will produce meaningful findings that are easily understandable to a wide audience. For example, stages of hypertension based on the values of blood pressure (Chobanian et al. 2003), graded severity of anemia on the basis of haemoglobin values (WHO, 2011) and the stages of chronic energy deficiency determined using the values of body mass index (James et al. 1988; WHO, 2004). The fundamental difference between the nominal and ordinal scale is that the nominal scale provides categorization of data only, whereas the ordinal scale rank the different categories according to some criterion/disease severity. The statistical operations for ordinal level data are very limited. The conventional methods such as chi-square tests, and non-parametric alternatives to t-tests and analysis of variance may be performed, but important information on the natural ordering of the categories would be lost (Bross, 1958; Agresti, 2010).

Bross (1958) developed the ridit analysis for handling of the ordinal data. The first three letters of the ridit stand for relative to an identified distribution and it named in analogy to probits and logits. The probits refers to a normal distribution, whereas, the ridit relates to an observed, empirical distribution under an ordered setup of the dependent variable. This method is used for comparing the ordinal scale responses such as the degree of pain, degree of injury, levels of satisfaction, preference or agreement (Dogan and Dogan, 2007). The ridit method has found applications in different fields of study, including epidemiology, biomedicine, psychology, animal studies, business management and behavioural studies (Wahi et al. 1965; Fleiss et al. 1979; Venkaiah et al. 1992; Donaldson, 1998; Feinstein 2002; Kaushal, 2013; Li et al. 2015; Han et al. 2015; Sadhukhan et al. 2015 and Origer et al. 2015). An excellent review on the ridit analysis and its uses are presented by Brockett \& Levine (1977), Selvin (1977), Jansen (1984), Fleiss (1986), Bullimore (1988), Beder\& Heim (1990), Sermeus\&Delesie (1996), Marion (1996), and Bilgin(2003). Ridit analysis is a useful and relatively simple method for ordinal level data, in the situations where the appropriateness of parametric and/or continuous data methods are unclear. The basic intent of the 
ridit analysis is to make comparisons across samples of relative frequency distributions of random variable measured on an ordinal scale (Schnell et al. 1995).

An attempt has been made to use the methodology of the ridit analysis to assess the severity of anemia among the children and pregnant women, across the different socio-demographic characteristics in Andhra Pradesh State in India. The association between the demographic variables and severity of anemia is studied using the Chi - square test. The ridits computed for each category of the demographic variables, and then tested homogeneity of the ridits using the Kruskal-Wallis test (K-W test). The statistical significance of differences between two mean ridits evaluated with a Z-test. The following section explains the computational procedure of ridits and the source of data.

\section{Methodology}

In riditanalysis, ordinal data of a particular group istransformed to a probability scale. The average ridit is an estimate of the chance that an individual in a given group is worse off or better off than an individual in the reference group. If a control group is readily available, then it can be considered as a reference group, otherwise, the distribution of the pooled data may be considered as an identified distribution. Ideally, a large sample establishes the reference distribution (Pouplard et al. 1997). The effective use of ridit analysis depends on the proper selection of identified or reference group (Kantor and Winkelstein, 1969). A computational procedure of ridit scores for the reference group or control group is given below:

Let there be $\mathrm{k}$ categories represent the lowest to highest severity of the disease or study criterion and the frequency in the $\mathrm{i}^{\text {th }}$ category of the reference group is $f_{i}$ for $\mathrm{i}=1,2, \ldots, \mathrm{k}$. The total number of observations in the reference group is $N=\sum_{i=1}^{k} f_{i}$. The ridit score of the $\mathrm{i}^{\text {th }}$ category in the reference group is given by $r_{i}=\left(\sum_{j=1}^{i-1} f_{j}+\frac{f_{i}}{2}\right) / N$ for $\mathrm{i}=1,2, \ldots, \mathrm{k}$. After computation of the ridits for the reference group, calculate the mean ridit of the comparison group or treatment group, which is like a weighted average, but in comparison to the reference group. To compute the mean ridit, multiply the frequency in each category by the reference ridit for that category, then sum up those products and divide by the 
total number of observations in the comparison group to get the mean ridit. Let the frequency in each category of the comparison group be $f_{t}$, where $\mathrm{t}=1,2, \ldots$, $\mathrm{k}$, then the total number of observations in comparison group is $n=\sum_{t=1}^{k} f_{t}$. The mean ridit for the $\mathrm{j}^{\mathrm{th}}$ comparison group is equal to $\bar{r}_{j}=\frac{1}{n} \sum_{t=1}^{k} f_{t} r_{t}$ where $r_{t}$ is the ridit of the $\mathrm{t}^{\text {th }}$ category in the reference group. The mean ridit of the reference group is always equivalent to 0.5 . As a probability, the mean ridit theoretically lies in between 0 and 1 . If a group's mean ridit is greater than 0.5 , its members tend to have more severe grade than the members of the reference group. The standard error of the average ridit is given by $S E(\bar{r})=1 /(2 \sqrt{3 n})$, where $\mathrm{n}=$ total frequency of the comparison group. Under the assumption of large samples, the approximate confidence intervals for the ridit of the $\mathrm{j}^{\text {th }}$ comparison group at the $5 \%$ level of significance is given by $\bar{r}_{j} \pm \frac{1}{\sqrt{3 n}}$. If the confidence interval of the $\bar{r}_{j}$ contain 0.5, then the null hypothesis is accepted that the $\bar{r}_{j}$ value is not significantly different from 0.5 or reference group. Since $\bar{r}_{j}$ represent the estimated probability of severity, hence a low value of $\bar{r}_{j}$ is preferred over a high value of $\bar{r}_{j}$. The Kruskal-Wallis $(\mathrm{K}-\mathrm{W})$ statistic used for testing the hypothesis of $\mathrm{H}_{0}: \bar{r}_{j}=0.5$ for all $\mathrm{j} ; \mathrm{H}_{1}: \bar{r}_{j} \neq 0.5$ for at least one $\mathrm{j}$; and the statistic is given by $W=12 \sum_{j=1}^{m} n_{j}\left(\bar{r}_{j}-0.5\right)^{2}$, where $\mathrm{j}=1,2, \ldots \mathrm{m}$ and $\mathrm{m}=$ number of comparison groups and the statistic has a Chi-Square distribution with (m-1) degrees of freedom. If the null hypothesis is rejected, there exists a significant difference in the disease patterns between the reference group and comparison groups. The difference between two mean ridits of the two different comparison groups $\left(\bar{r}_{1}\right.$ and $\left.\bar{r}_{2}\right)$ having the same reference group is tested by the statistic $Z=\frac{2\left(\bar{r}_{1}-\bar{r}_{2}\right) \sqrt{3 n_{1} n_{2}}}{\sqrt{\left(n_{1}+n_{2}\right)}} \sim N(0,1)$ where $n_{1}$ and $n_{2}$ are the total frequency of the comparison groups. A two-tailed $\mathrm{p}$ value $<0.05$ was considered statistically significant. All the statistical computations are performed using a $\mathrm{C}$ program and MS Excel software. 
An attempt is made to illustrate the utility and usefulness of ridit analysis using the prevalence data on anemia among the children, adolescents and pregnant women by selected demographic characteristics reported in the fourth round of the District Level Household and Facility Survey (DLHS-4) of Andhra Pradesh state conducted during 2012-13. The data presents the anemia status based on the haemoglobin level, is categorized into the four levels namely, normal $(\geq 11.0 \mathrm{~g} / \mathrm{dl})$, mild anemia (10.0-10.9 g/dl), moderate anemia (7.0-9.9 g/dl) and severe anemia $(<7.0 \mathrm{~g} / \mathrm{dl})$ (WHO, 2011). For the ridit analysis, the distribution for the entire sample will serve as the reference group under each one of the demographic characteristics of the respondents.

\section{Results and Discussion}

The prevalence of anemia is $79.2 \%$ and $71.6 \%$, respectively, for the children (659 months) and pregnant women in the state. The prevalence of severe anemia is about $10 \%$ among the school going children and adolescents (6-19 years) in the state. The prevalence of severe anemia is observed highest $(21.2 \%)$ among the children aged 6-59 months as compared to the other children and pregnant women in the state (DLHS-4). Table 1 shows the distribution of the children aged 6-59 months, according to their demographic characteristics and severity of anemia. A significant association between residence area and anemia severity among the children is observed by Chi-square $\left(\chi^{2}\right)$ test $(\mathrm{p}<0.05)$ and there is no significant association between the gender and caste with the anemia severity among the under five year old children in the state. The mean ridits for the below five year old children suggest that, the anemia severity is higher in boys, rural children, Scheduled caste (SC) and Scheduled Tribes (ST) children in the state. The mean ridit for ST children is 0.527 and is the estimated probability that a randomly selected child from this group have a greater severity of anemia than a randomly selected child from the reference group. If a ridit value less than the 0.5 , we would infer that, a child likely to have less severity of anemia than the children of the reference group. Urban children are less likely to be in a higher severity of anemia than the reference group. The Kruskal-Wallis (K-W) test reveals that, the mean ridits of rural and urban children are significantly different from the reference group. 


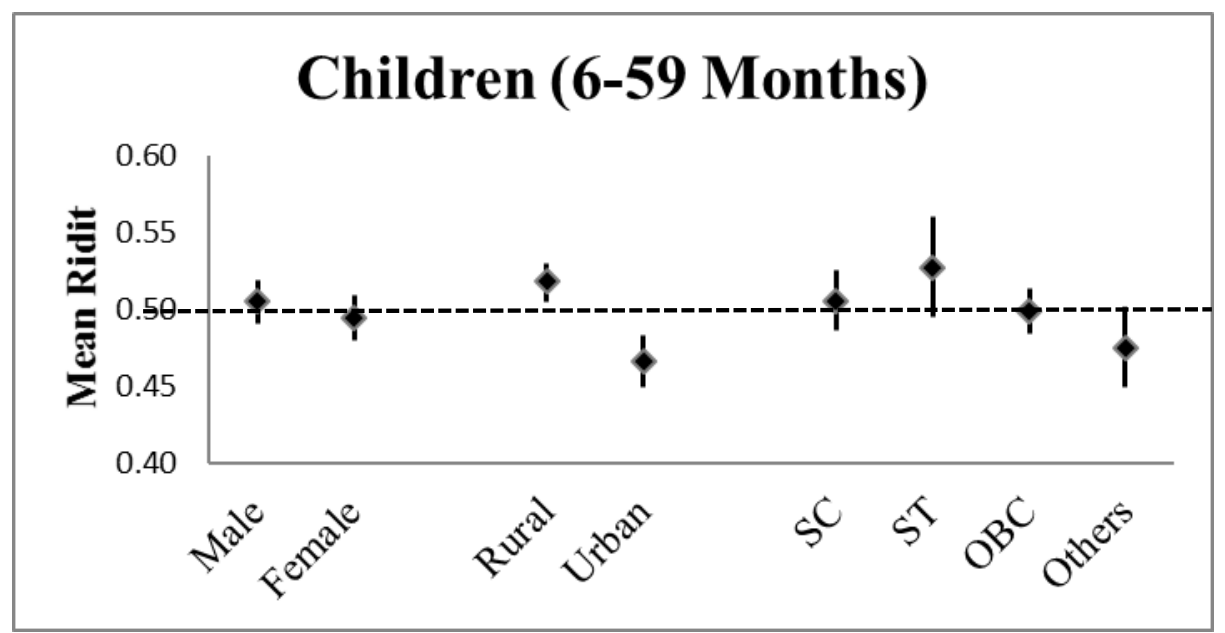

Figure 1. Confidence intervals of the mean ridits for severity of anemia among the below five year old children in Andhra Pradesh

Figure 1 provides the mean ridits and their confidence intervals. There is an evidence that, two of the eight groups differ substantially from the reference group (ridit $<0.5$ ). The prevalence of severe anemia is comparatively less in urban children and also in the children of other castes (OCs).

Table 2 shows the pair wise comparison of the mean ridits of different groups associated with the below five year old children. There is a significant difference in the mean ridits of rural and urban children and rural children have higher prevalence of severe anemia as compared to the urban children. Similarly, there is a significant difference between the mean ridits of ST and OCs, where severity of anemia is observed more in ST children as compared to the children from the community of OCs. 


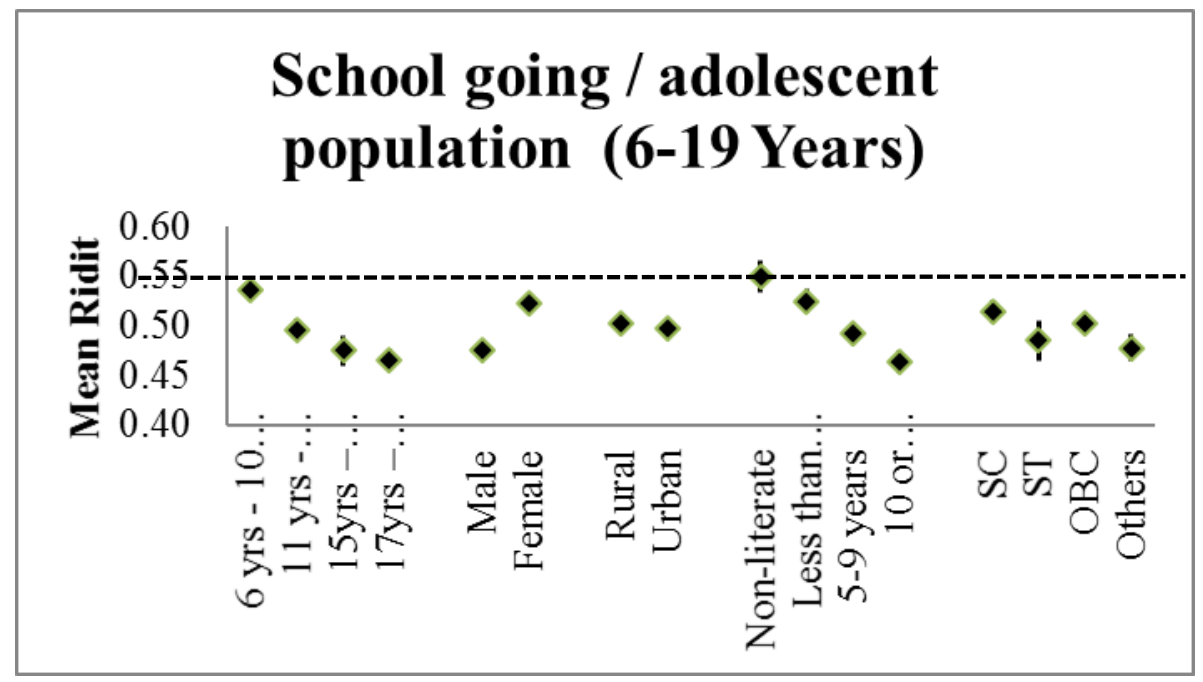

Figure 2. Confidence intervals of the mean ridits for severity of anemia among the school going/adolescent population (6-19 year old) in Andhra Pradesh.

Figure 2 shows a clear trend in the mean ridits for age of the respondents and education status. The pair wise comparisons (Table 4) show a significantdifference in the mean ridits among the respondents aged below 16 years. The mean ridits are significantly different in both of the genders. The severity of anemia is statistically similar in the respondents from the urban and rural areas.

The Chi-square analysis reveals that, the severity of anemia significantly associated with the age, gender, residence area, education and caste of school going children and adolescent population (aged 6-19 years). The mean ridit score is decreasing as the age of the respondents is increasing and also observed that, the children having age in between 6-10 years are likely to have a higher severity of anemia as compared to the children of reference group. Female respondents are more likely to have a higher severity of anemia as compared to the reference group. The mean ridits are decreasing as the education level increases and the respondents with low level of education are likely to have a higher severity of anemia as compared to the respondents from the reference group. There is a higher chance of anemia severity among SC children as compared to the children from the reference group (Table 3).

The K-W test shows that, the mean ridits of the age groups, gender, education status and caste groups are significantly different from the mean ridit of the reference group. We can rank the caste categories on the basis of their ridit scores 
from lowest to highest severity, which results the ordering as OCs first, STs second, other backward castes (OBCs) third and SC are lying on the last of the scale of anemia severity. Similarly, 10 or more years of education is first, 5-9 years of education is second, less than five years of education is third and nonliterates are lying on the last of the scale of anemia severity (Table 3). It is observed that, the chance of severe anemia is statistically significant in SC andSTs, SC andOCs and OBC andOCs (Table 4).

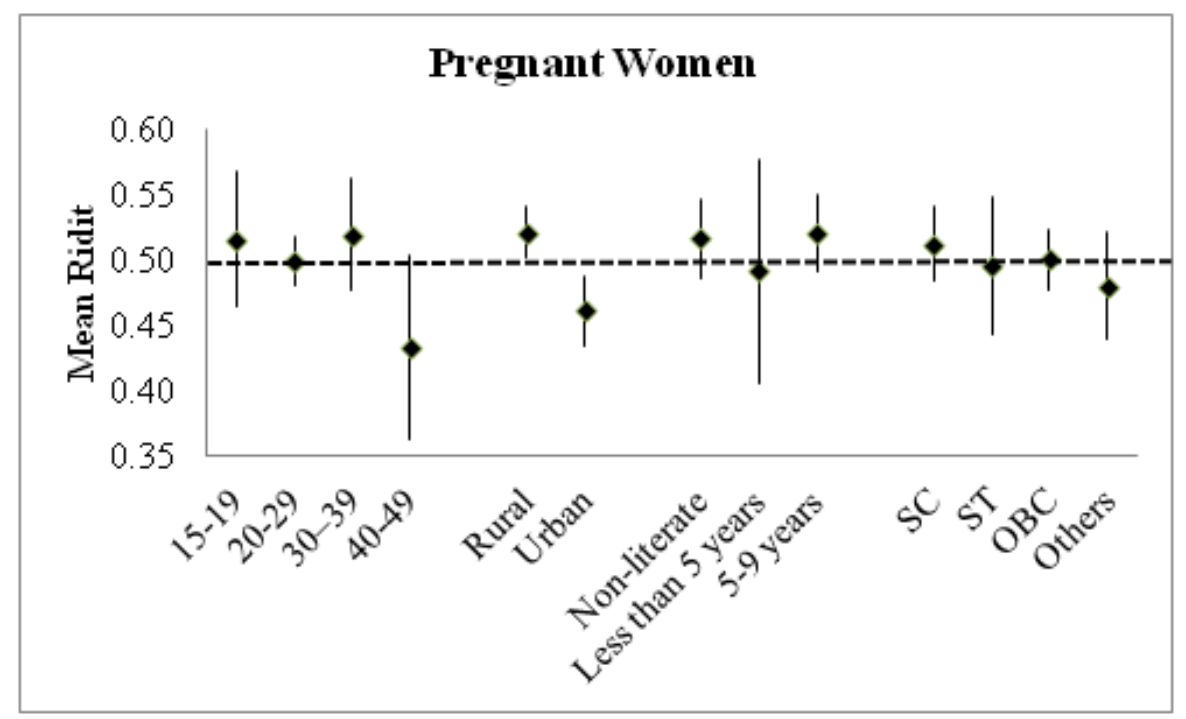

Figure 3. Confidence intervals of the mean ridits for severity of anemia among the pregnant women in Andhra Pradesh

It is clear that, the pregnant women in the age group 40-49 years are likely to have low severity of anemia as compared to the pregnant women from the other age groups. The mean ridit of severity of anemia in pregnant women with age 30-39 and 40-49 is statistically significant at the 5\% level of significance. The mean ridits of rural and urban subjects are also significant. The mean ridits of pregnant women with the education status as non-literate and 10 or more years of education are significant; similarly, the severity of anemia in the groups of 5-9 years of education and ten or more years of education are also significant at the $5 \%$ level of significance (Figure 3, Table 6).

The Chi-Square tests shows that, the residential area and the anemia severity are significantly associated at $5 \%$ level of significance. The mean ridits for the pregnant women aged 15-19 years and 30-39 years havemore than 0.5 p-values, which imply that, a randomly selected pregnant woman from these two age groups have a higher estimated probability of severe anemia as compared to the 
pregnant women from the reference group (Table 5). It is observed from Table 6, there are no significant differences in the distribution of the severity of anemia among the pregnant women in different caste groups. However, there is a significant difference is observed between the residential area and the severity of anemia among the pregnant women.

It is observed that, there is an impact of residential area on the severity of anemia among under five year old children and pregnant women in the Andhra Pradesh state. Gender and caste are also highly associated with the severity of anemia among the school going children/adolescents aged 6-19 years in. The lower risk of severe anemia observed among the children and pregnant women from the OCs as compared to $\mathrm{SC} / \mathrm{STs}$ in the state.

\section{Conclusion}

The anemia severity distribution is significantly different in rural and urban areas among under five year old children and pregnant women in Andhra Pradesh state. Similarly, the anemia severity pattern is different in males and females aged between 6-19 years.The risk of anemia severity reduces as the age and education status of the respondents increasesin the school going and adolescent population.

The ridit analysis is considered to be a better choice for analyzing the ordinal categorical data, as compared to the Chi-square test, as it takes care of ordering. This method can also be applied to the contingency tables with low cell frequencies and it does not require entire data, unlike, in the logistic regression methods. Moreover, the ridit method can also be used to rank the demographic characteristics on the basis of the ridit scores of the disease severity and it can also be used for identifying the key characteristics associated with the severity of the disease. In conclusion, the ridit method is simple, easy to compute and does not require any sophisticated software to analyze data.

\section{Acknowledgements}

Authors are very thankful to the Director, National Institute of Nutrition, Hyderabad for supporting us to carry out this research and also thankful to IIPS, Mumbai for providing the Andhra Pradesh State report under DLHS-4. The authors also thankful to the referees for their valuable comments and suggestions which helped in improving the article. 


\section{References}

1. Agresti A. (2010). Analysis of Ordinal Categorical Data. 2nd edn. New York: Wiley.

2. BederJ.H.and Heim R.C. (1990). On the use of ridit analysis. Psychometrica, 55: 603-616.

3. Bilgin O.C (2003). Ridit analysis and its use. Ataturk Univ. ZiraatFak, Derg., 34(2): 135-138.

4. Brockett P.L. and Levine A. (1977). On a Characterization of Ridits, The Annals of Statistics, 5(6): 1245-1248.

5. Bross I.D. (1958). How to Use Ridit Analysis. Biometrics, 14 (1): 18-38.

6. Bullimore D. (1988). RIDIT analysis for qualitative and subjective clinical data, Aliment. Pharmacol. Therap., 2: 43-45.

7. Chobanian A.V., Bakris G.L., Black H.R., Cushman W.C., Green L.A., Izzo J.L. Jr, et al. (2003). The seventh report of the Joint National Committee on Prevention, Detection, Evaluation, and Treatment of High Blood Pressure: the JNC 7 report. JAMA 2003; 289: 2560-72.

8. District Level Household and Facility Survey-2012-13 (DLHS-4). International Institute for Population Sciences (IIPS), Mumbai, India.

9. Dogan I. and Dogan N. (2007). A review on the ridit analysis. TURKSTAT, Journal of Statistical Research, 5 (2): 69-77.

10. Donaldson G.W. (1998). Ridit scores for analysis and interpretation of ordinal pain data. European Journal of Pain, 2: 221-227.

11. Feinstein A.R. (2002). Principles of medical statistics. Chapman \& Hall/CRC.

12. Fleiss J.L., Chilton N.W., Wallenstein S. (1979). Ridit Analysis in Dental Clinical Studies. J. Dent. Res., 58 (11): 2080-2084.

13. Fleiss J.L. (1986). The Design and Analysis of Clinical Experiments. New York: John Wiley \& Sons.

14. Han Y., Xu Q., Hu J., Han X., Li W., Zhao L. (2015). Maltol, a Food Flavoring Agent, Attenuates Acute Alcohol-Induced Oxidative Damage in Mice, Nutrients, 7: 682-696.

15. James W.P.T., Anna Ferro-Lyzzi and Waterlow J.C. (1988). Definition of Chronic Energy Deficiency in Adults, European Jour. of Clin. Nutr. 42: 969-981.

16. Jansen M. E. (1984). Ridit analysis, a review. StatisticaNeerlandica, 38(3): 141158.

17. Kantor S. and Winkelstein W. (1969). The rationale and use of ridit analysis in epidemiologic studies of blood presseure. American Journal of epidemiology, 90 (3): 201-213. 
18. Kaushal S.K. (2013). The importance of apparel product attributes for teenaged buyers. NMIMS Management Review, XXIII: 45-65.

19. Li R., Liu J., Chen W., Duan Y., Yang Y., Hu Z., Tan X., Zhong M. and Zhuge Q. (2015). An experimental study on multi-slices CT angiography of the basilar artery in rabbit model of cerebral vasospasm. International Conference on Materials Engineering and Information Technology Applications (MEITA 2015), 584-590.

20. Marion M.A. (1996). Severity Analysis Using Ridits, Posters, Annual international conference; $21^{\text {st }}$ - SAS Users Group; Chicago; IL.

21. Origer A., Le Bihan E. and Baumann M. (2015). A Social Gradient in Fatal Opioids and Cocaine Related Overdoses?, PLoS ONE, 10(5), e0125568.

22. Pouplard N., Quannari E.M. and Simon S. (1997). Use of ridits to analyse categorical data in preference studies. Food quality \& preference, 8 (5/6): 419-422.

23. Sadhukhan S.S., Banerjee U.K. and Maitra B. (2015). Commuters' Perception towards Transfer Facility Attributes in and Around Metro Stations: Experience in Kolkata. Journal of Urban Planning and Development, 141 (4): 04014038.

24. Schnell D.J., Magee E. and Sheridan J.R. (1995). A regression method for analysing ordinal data from intervention trials. Statistics in Medicine, 14: 1177-1189.

25. Selvin S. (1977). A further note on the interpretation of ridit analysis. American Journal of Epidemiology, 105 (1): 16-20.

26. Sermeus W., Delesie L. (1996). Ridit analysis on ordinal data. West. J. Nurs. Res., 18: 351-359.

27. Venkaiah K., Kulkarni PK., Mohan R.N., Saiyed H.N. and Kashyap S.K. (1992). Some of the statistical techniques in the evaluation of occupational health problems. Ind. J. Indust. Med, 38: 17-22.

28. Wahi P.N., Lahiri B., Kehar U. and Arora S. (1965). Oral and Oropharyngeal cancers in north India. British Journal of Cancer, XIX (4): 627-641.

29. WHO (2004). WHO expert consultation, Appropriate body-mass index for Asian populations and its implications for policy and intervention strategies. The Lancet, 363: 157-163.

30. WHO (2011). Haemoglobin concentrations for the diagnosis of anaemia and assessment of severity. Vitamin and Mineral Nutrition Information System. World Health Organization, Geneva. 
Table 1. Distribution (\%) and Ridit scores for iron-deficiency (anemia) among the children age (6-59 months) by selected demographic characteristics in Andhra Pradesh

\begin{tabular}{|c|c|c|c|c|c|c|c|c|c|c|c|c|}
\hline & \multicolumn{4}{|c|}{ Anemia Severity } & \multirow[b]{2}{*}{ Total } & \multirow[b]{2}{*}{$\chi^{2}$} & \multirow[b]{2}{*}{$\mathrm{df}$} & \multirow[b]{2}{*}{$\mathrm{p}$} & \multirow[b]{2}{*}{ Ridit } & \multirow[b]{2}{*}{$\begin{array}{l}\text { K-W } \\
\text { Test }\end{array}$} & \multirow[b]{2}{*}{ df } & \multirow[b]{2}{*}{$\mathrm{P}$} \\
\hline & Normal & Mild & Moderate & Severe & & & & & & & & \\
\hline \multicolumn{13}{|l|}{ Gender } \\
\hline $\begin{array}{l}\text { Male } \\
\text { Female } \\
\text { Residen }\end{array}$ & $\begin{array}{l}330 \\
(20.3) \\
316 \\
(21.3) \\
\text { e Area }\end{array}$ & $\begin{array}{l}192 \\
(11.8) \\
193 \\
(13.0)\end{array}$ & $\begin{array}{l}752 \\
(46.3) \\
667 \\
(45.0)\end{array}$ & $\begin{array}{l}351 \\
(21.6) \\
307 \\
(20.7)\end{array}$ & $\begin{array}{c}1625 \\
(100) \\
1483 \\
(100)\end{array}$ & 1.86 & 3 & 0.60 & $\begin{array}{l}0.505 \\
0.494\end{array}$ & 1.13 & 1 & 0.29 \\
\hline $\begin{array}{l}\text { Residen } \\
\text { Rural } \\
\text { Urban }\end{array}$ & $\begin{array}{l}\text { e Area } \\
395 \\
(19.3) \\
267 \\
(25.1)\end{array}$ & $\begin{array}{l}237 \\
(11.6) \\
154 \\
(14.5)\end{array}$ & $\begin{array}{l}953 \\
(46.6) \\
456 \\
(42.9)\end{array}$ & $\begin{array}{l}460 \\
(22.5) \\
186 \\
(17.5)\end{array}$ & $\begin{array}{c}2045 \\
(100) \\
1063 \\
(100)\end{array}$ & \multirow[t]{2}{*}{26.24} & 3 & 0.00 & $\begin{array}{l}0.518 \\
0.466\end{array}$ & \multirow[t]{2}{*}{22.29} & 1 & 0.00 \\
\hline \multicolumn{11}{|l|}{ Caste } & & \\
\hline $\mathrm{SC}$ & $\begin{array}{l}177 \\
(20.4)\end{array}$ & $\begin{array}{l}107 \\
(12.3)\end{array}$ & $\begin{array}{l}393 \\
(45.2)\end{array}$ & $\begin{array}{l}192 \\
(22.1)\end{array}$ & $\begin{array}{l}869 \\
(100)\end{array}$ & \multirow{4}{*}{10.92} & \multirow{4}{*}{9} & & 0.505 & \multirow{4}{*}{6.66} & \multirow{4}{*}{3} & \multirow{4}{*}{0.08} \\
\hline ST & $\begin{array}{l}50 \\
(16.4)\end{array}$ & $\begin{array}{l}33 \\
(10.8)\end{array}$ & $\begin{array}{l}155 \\
(50.8)\end{array}$ & $\begin{array}{l}67 \\
(22.0)\end{array}$ & $\begin{array}{l}305 \\
(100)\end{array}$ & & & & 0.527 & & & \\
\hline $\mathrm{OBC}$ & $\begin{array}{l}310 \\
(21.4)\end{array}$ & $\begin{array}{l}177 \\
(12.2)\end{array}$ & $\begin{array}{l}651 \\
(44.9)\end{array}$ & $\begin{array}{l}312 \\
(21.5)\end{array}$ & $\begin{array}{c}1450 \\
(100)\end{array}$ & & & 0.28 & 0.499 & & & \\
\hline Others & $\begin{array}{l}110 \\
(22.7)\end{array}$ & $\begin{array}{l}68 \\
(14.0)\end{array}$ & $\begin{array}{l}220 \\
(45.5)\end{array}$ & $\begin{array}{l}86 \\
(17.8)\end{array}$ & $\begin{array}{l}484 \\
(100)\end{array}$ & & & & 0.475 & & & \\
\hline
\end{tabular}

Figures in parenthesis are percentages and are calculated row -wise.

Source:Andhra Pradesh: District Level Household and Facility Survey (DLHS-4), 2012-13. 
Table 2. Pairwise comparisons of mean ridits of anemia severity among children age (6-59 months) in Andhra Pradesh

\begin{tabular}{llcc}
\hline Group-1 & Group-2 & $\mathrm{Z}$ & $\mathrm{P}$ \\
\hline Male & Female & 1.06 & 0.29 \\
Rural & Urban & 4.72 & 0.00 \\
SC & ST & -1.15 & 0.25 \\
SC & OBC & 0.50 & 0.61 \\
SC & Others & 1.85 & 0.06 \\
ST & OBC & 1.55 & 0.12 \\
ST & Others & 2.48 & 0.01 \\
OBC & Others & 1.58 & 0.11 \\
\hline
\end{tabular}

Source: Author's computations based on DLHS-4.

Table 3. Distribution (\%) and Ridit scores for iron-deficiency (anemia) among school going/adolescent population (6-19 years) by selected demographic characteristics in Andhra Pradesh

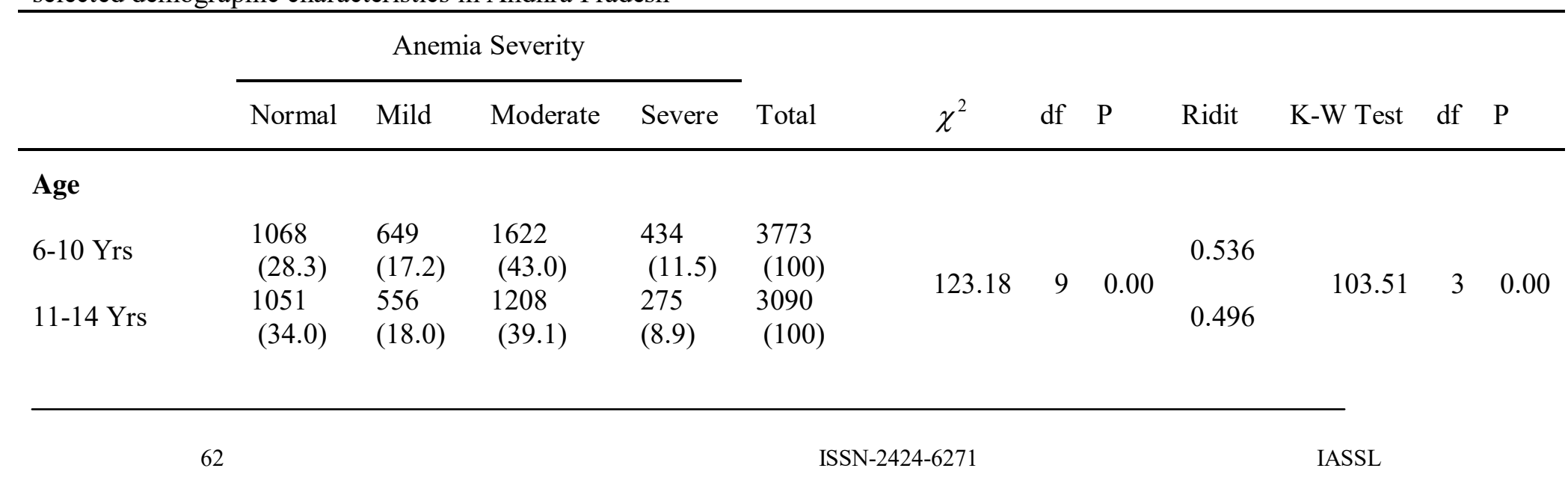




$\begin{array}{llllccr}15-16 \text { Yrs } & 543 & 260 & 525 & 117 & 1445 & 0.475 \\ & (37.6) & (18.0) & (36.3) & (8.1) & (100) & 0.466 \\ 17-19 \text { Yrs } & 1021 & 423 & 889 & 214 & 2547 & (100)\end{array}$

\section{Gender}

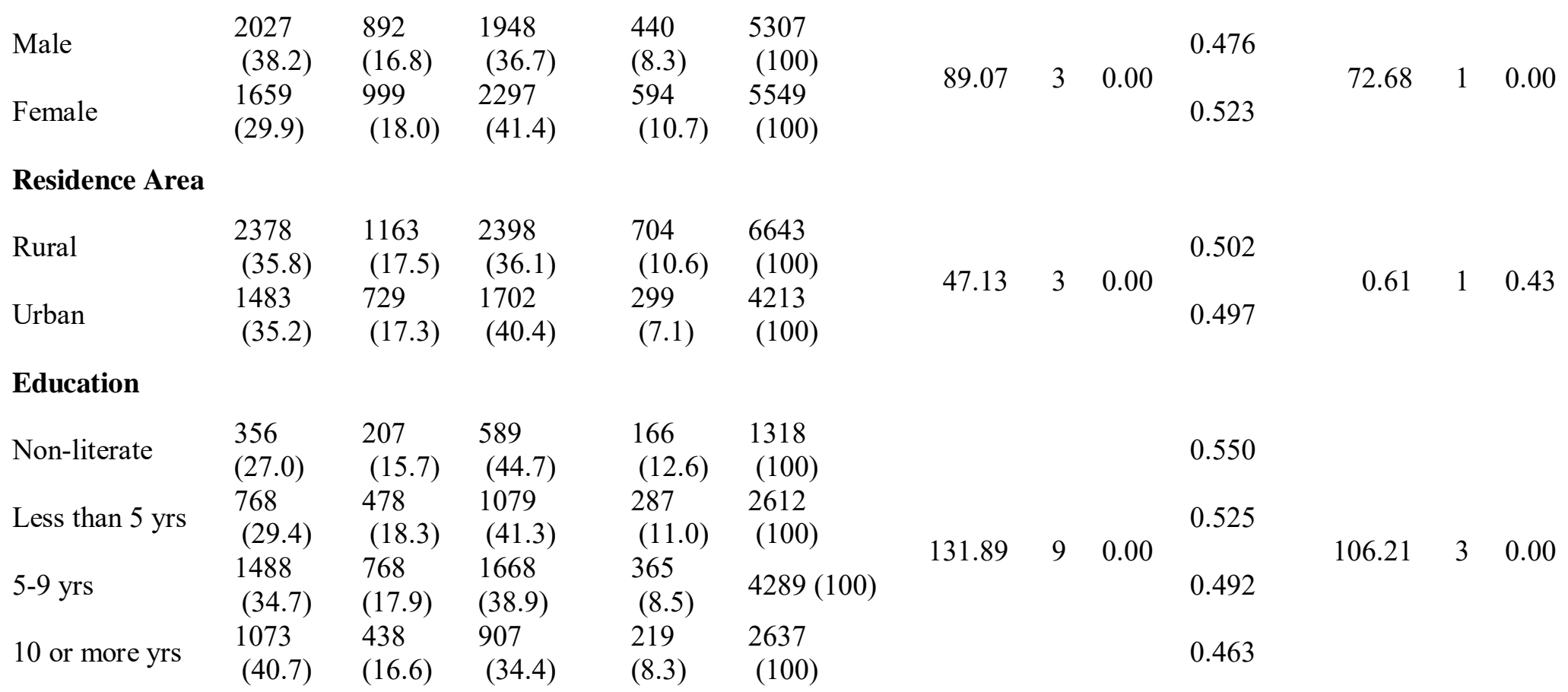

\section{Caste}




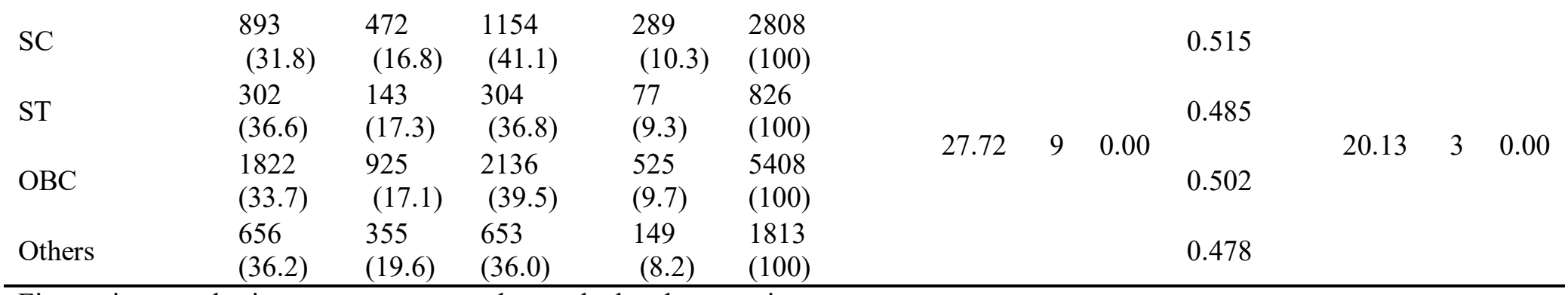

Figures in parenthesis are percentages and are calculated row -wise.

Source: Andhra Pradesh: District Level Household and Facility Survey (DLHS-4), 2012-13.

Table 4. Pairwise comparisons of mean ridits of anemia severity among school going/adolescent population (6-19 years) in Andhra Pradesh

\begin{tabular}{llrr}
\hline Group-1 & Group-2 & $\mathrm{Z}$ & $\mathrm{P}$ \\
\hline 6-10 Yrs & $11-14$ Yrs & 5.62 & 0.00 \\
6-10 Yrs & $15-16$ Yrs & 6.77 & 0.00 \\
6-10 Yrs & $17-19$ Yrs & 9.37 & 0.00 \\
11-14 Yrs & $15-16$ Yrs & 2.30 & 0.02 \\
$11-14$ Yrs & $17-19$ Yrs & 0.99 & 0.00 \\
15-16 Yrs & $17-19$ Yrs & -8.53 & 0.35 \\
Male & Female & 0.78 & 0.00 \\
Rural & Urban & 2.47 & 0.43 \\
Non-literate & Less than 5 yrs & 6.33 & 0.01 \\
Non-literate & $5-9$ yrs & 0.00 \\
\hline
\end{tabular}




\begin{tabular}{llrl}
\hline Non-literate & 10 or more yrs & 8.91 & 0.00 \\
Less than 5 yrs & $5-9$ yrs & 4.67 & 0.00 \\
Less than 5 yrs & 10 or more yrs & 7.86 & 0.00 \\
5-9 years & 10 or more yrs & 2.08 & 0.00 \\
SC & ST & 1.85 & 0.01 \\
SC & OBC & 4.20 & 0.06 \\
SC & Others & -1.58 & 0.00 \\
ST & OBC & 0.58 & 0.11 \\
ST & Others & 3.07 & 0.56 \\
OBC & Others & 0.00 \\
\hline
\end{tabular}

Source: Author's computations based on DLHS-4.

Table 5. Distribution (\%) and Ridit scores for iron-deficiency (anemia) among pregnant women by selected demographic characteristics in Andhra Pradesh

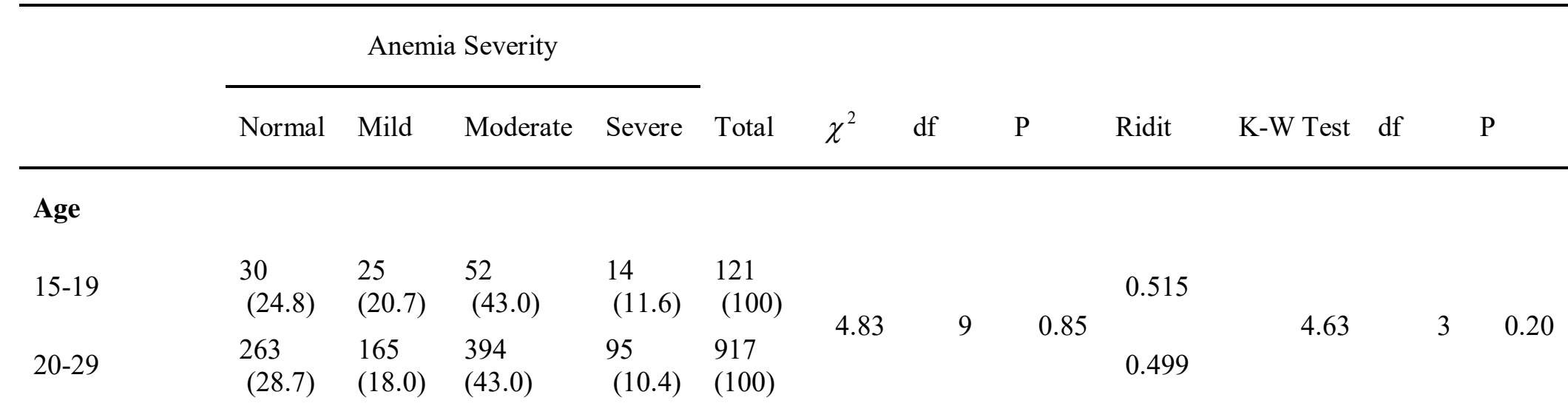




$\begin{array}{llllccc}30-39 & 46 & 28 & 74 & 22 & 170 & 0.519 \\ & (27.1) & (16.5) & (43.5) & (12.9) & (100) & \\ 40-49 & 24 & 14 & 23 & 4 & 65 & 0.433\end{array}$

\section{Residence Area}

\begin{tabular}{|c|c|c|c|c|c|c|c|c|c|c|c|}
\hline Rural & $\begin{array}{l}222 \\
(26.5)\end{array}$ & $\begin{array}{l}144 \\
(17.2)\end{array}$ & $\begin{array}{l}377 \\
(45.0)\end{array}$ & $\begin{array}{l}94 \\
(11.2)\end{array}$ & $\begin{array}{l}837 \\
(100)\end{array}$ & 565 & 3 & 00 & 17 & 1 & 00 \\
\hline Urban & $\begin{array}{l}148 \\
(33.9)\end{array}$ & $\begin{array}{l}94 \\
(21.5)\end{array}$ & $\begin{array}{l}157 \\
(35.9)\end{array}$ & $\begin{array}{l}38 \\
(8.7)\end{array}$ & $\begin{array}{l}437 \\
(100)\end{array}$ & 15.65 & 3 & 0.00 & 1 & 1 & 0 \\
\hline
\end{tabular}

\section{Education}

$\begin{array}{llllllllll}\text { Non-literate } & 95 & 64 & 151 & 45 & 355 & & & 0.516 & \\ & (26.8) & (18) & (42.5) & (12.7) & (100) & & & \\ \text { Less than 5 yrs } & 13 & 7 & 21 & 3 & 44 & & 0.492 & 0.08 \\ & (29.5) & (15.9) & (47.7) & (6.8) & (100) & 11.65 & 9 & 0.23 & \\ 5-9 \text { years } & 89 & 68 & 172 & 37 & 366 & & 0.52 & \\ & (24.3) & (18.6) & (47) & (10.1) & (100) & & & \\ 10 \text { or more yrs } & 166 & 94 & 199 & 50 & 509 & & & \\ & (32.6) & (18.5) & (39.1) & (9.8) & (100) & \end{array}$




\section{Caste}

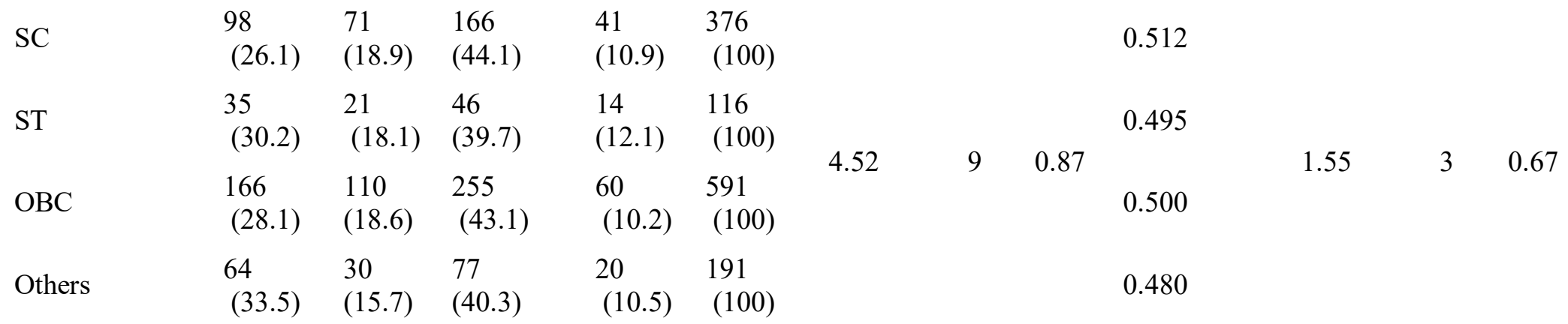

Figures in parenthesis are percentages and are calculated row -wise.

Source: Andhra Pradesh: District Level Household and Facility Survey (DLHS-4), 2012-13.

Table 6. Pairwise comparisons of mean ridits of anemia severity among pregnant women in Andhra Pradesh

\begin{tabular}{llcc}
\hline Group-1 & Group-2 & Z & P \\
\hline $15-19$ & $20-29$ & 0.574 & 0.57 \\
$15-19$ & $30-39$ & -0.123 & 0.90 \\
$15-19$ & $40-49$ & 1.855 & 0.06 \\
$20-29$ & $30-39$ & -0.839 & 0.40 \\
$20-29$ & $40-49$ & 1.791 & 0.07 \\
$30-39$ & $40-49$ & 2.057 & 0.04 \\
Rural & Urban & 3.489 & 0.00 \\
\hline
\end{tabular}




\begin{tabular}{llcc}
\hline Non-literate & Less than 5 yrs & 0.523 & 0.60 \\
Non-literate & $5-9$ yrs & -0.216 & 0.83 \\
Non-literate & 10 or more yrs & 2.206 & 0.03 \\
Less than 5 yrs & $5-9$ yrs & -0.625 & 0.53 \\
Less than 5 yrs & 10 or more yrs & 0.360 & 0.72 \\
5-9 years & 10 or more yrs & 2.279 & 0.02 \\
SC & ST & 0.542 & 0.59 \\
SC & OBC & 0.634 & 0.53 \\
SC & Others & 1.229 & 0.20 \\
ST & OBC & -0.155 & 0.88 \\
ST & Others & 0.439 & 0.66 \\
OBC & Others & 0.810 & 0.42 \\
\hline Sors
\end{tabular}

Source: Author's computations based on DLHS-4 